\title{
The Characterization and Hydrogen Production from Water Decomposition with Methanol in a Semi-Batch Type Reactor Using In, P-TiO ${ }_{2} \mathrm{~S}$
}

\author{
Joonwoo Kim, ${ }^{1}$ Hae-Ri Kim, ${ }^{2}$ and Suk-Jin Choung1 \\ ${ }^{1}$ Department of Chemical Engineering, Kyung Hee University, Yongin-Si, Gyeonggi-Do 446-701, Republic of Korea \\ ${ }^{2}$ Technical Center, Ordeg Corporation, Mognae-Dong, Ansan 425-100, Republic of Korea \\ Correspondence should be addressed to Suk-Jin Choung, sjchoung@khu.ac.kr
}

Received 14 December 2010; Revised 11 February 2011; Accepted 17 February 2011

Academic Editor: Roel van De Krol

Copyright (C) 2011 Joonwoo Kim et al. This is an open access article distributed under the Creative Commons Attribution License, which permits unrestricted use, distribution, and reproduction in any medium, provided the original work is properly cited.

The photocatalytic production of hydrogen from water using solar energy is potentially a clean and renewable source for hydrogen fuel. This study examines the production of hydrogen over In, $\mathrm{P}-\mathrm{TiO}_{2}$ s photocatalysts. $1 \mathrm{~mol} \% \mathrm{In}-\mathrm{TiO}_{2}$ and $\mathrm{P}-\mathrm{TiO}{ }_{2}$ were produced using the solvothermal method and were treated at 500 and $800^{\circ} \mathrm{C}$ to obtain anatase and rutile structure, respectively. The photocatalysts were characterized by X-ray diffraction, photoluminescence spectra, X-ray spectroscopy, UV-visible spectroscopy, and scanning electron microscopy. The production of $\mathrm{H}_{2}$ from methanol photodecomposition was greater over the rutile structure than over the anatase structure of $\mathrm{TiO}_{2}$. Moreover, the amount of hydrogen was enhanced over In- $-\mathrm{TiO}{ }_{2}$ and $\mathrm{P}-\mathrm{TiO}{ }_{2}$ compared to that over pure $\mathrm{TiO}_{2}$; the production increased by about $30 \%$. The structural effect and the addition of In, $\mathrm{P}$ have significant influence on the $\mathrm{H}_{2}$ production from methanol/water decomposition.

\section{Introduction}

The importance of hydrogen as a source of fuel in the near future is due to its application as a compact energy supplier in fuel cells and batteries. Hydrogen fuel can be produced from clean and renewable energy resources, and thus, its life cycle is clean and renewable. Compared to the conventional and expensive methods, the photocatalytic splitting of water using $\mathrm{TiO}_{2}$ offers a promising way for clean, low-cost, and environmentally friendly production of hydrogen using solar energy. Early work of $\mathrm{TiO}_{2}$-assisted photo-electrochemical hydrogen production was reported by Fujishima and Honda [1]. Since then, the technology for generating hydrogen by the splitting of water using a photocatalyst has attracted much attention. Recently, hydrogen production has been extended to the photocomposition of methanol which has a lower splitting energy than water. Kawai and Sakata suggested the following overall methanol decomposition reaction $[2,3]$ :

$$
\begin{array}{r}
\mathrm{CH}_{3} \mathrm{OH}(\mathrm{l}) \longleftrightarrow \mathrm{HCHO}(\mathrm{g})+\mathrm{H}_{2}(\mathrm{~g}), \\
\Delta \mathrm{G}_{1}{ }^{\circ}=64.1 \mathrm{kJmol}^{-1},
\end{array}
$$

$$
\begin{gathered}
\mathrm{HCHO}(\mathrm{g})+\mathrm{H}_{2} \mathrm{O}(\mathrm{l}) \longleftrightarrow \mathrm{HCO}_{2} \mathrm{H}(\mathrm{l})+\mathrm{H}_{2}(\mathrm{~g}), \\
\Delta \mathrm{G}_{2}{ }^{\circ}=47.8 \mathrm{kJmol}^{-1}, \\
\mathrm{HCO}_{2} \mathrm{H}(\mathrm{l}) \longleftrightarrow \mathrm{CO}_{2}(\mathrm{~g})+\mathrm{H}_{2}(\mathrm{~g}) \\
\Delta \mathrm{G}_{3}{ }^{\circ}=-95.8 \mathrm{kJmol}^{-1} .
\end{gathered}
$$

Overall,

$$
\begin{array}{r}
\mathrm{CH}_{3} \mathrm{OH}(\mathrm{l})+\mathrm{H}_{2} \mathrm{O}(\mathrm{l}) \longleftrightarrow \mathrm{CO}_{2}(\mathrm{~g})+3 \mathrm{H}_{2}(\mathrm{~g}), \\
\Delta \mathrm{G}^{\circ}=16.1 \mathrm{kJmol}^{-1} .
\end{array}
$$

Consequently, the decomposition energy for methanol is $0.7 \mathrm{eV}$. Most investigations of hydrogen production via methanol photodecomposition have focused on modifying $\mathrm{TiO}_{2}$ in many reports, and the photocatalytic method is modified either by anion doping or metal ion doping or by loading with noble metals. Anpo and Takeuchi suggested $\mathrm{Pt} / \mathrm{TiO}_{2}$ [4], Bamwenda et al. compared Au-loaded $\mathrm{TiO}_{2}$ and Pt-loaded $\mathrm{TiO}_{2}$ [5], Sakthivel et al. used $\mathrm{Pt}, \mathrm{Au}$, and 
Pd-loaded $\mathrm{TiO}_{2}$ [6], Wu et al. studied $\mathrm{CuO}_{x} / \mathrm{TiO}_{2}$ [7], and Park and Kang used Ag-incorporated $\mathrm{TiO}_{2}$ [8]. In the case of metal ion doping, transitional metal ion doping and rare earth metal ion doping have been extensively developed for enhancing the $\mathrm{TiO}_{2}$ photocatalytic activities. Choi et al. studied the photocatalytic activity of 21 metal ions doped into $\mathrm{TiO}_{2}$, and among of them, Fe, Mo, Ru, Os, Re, and V ions exhibited good activity [9]. Some of the recent reports have studied the photo-electrochemical characteristics of anion (N, F, C, S, etc.) doped $\mathrm{TiO}_{2}$ powder and colloidal materials under UV-visible and visible illumination [10-13]. However, rapid electron-hole recombination and thermal instability are thought to be the major impediments. However, the number of known photocatalysts is limited, and their activity is still low. There is an urgent need to develop new photocatalysts that have greater hydrogen-producing activity under visible light irradiation.

In this study, we evaluated two new materials, In- $\mathrm{TiO}_{2}$ and $\mathrm{P}-\mathrm{TiO}_{2}$, to reduce the large band gap of pure $\mathrm{TiO}_{2}$. To investigate the structural effect of the photocatalysts, we prepared the photocatalysts with anatase and rutile structures using thermal treatment at 500 and $800^{\circ} \mathrm{C}$, respectively which were then used to produce hydrogen gas via methanol photodecomposition. To determine the relationship between In, $\mathrm{P}$ species and catalytic performance for $\mathrm{H}_{2}$ production, the $\mathrm{In}-\mathrm{TiO}_{2}$ and $\mathrm{P}-\mathrm{TiO}_{2}$ photocatalysts were examined using $\mathrm{X}$-ray diffraction, photoluminescence, $\mathrm{X}$-ray photon spectroscopy, and UV-Visible spectroscopy.

\section{Experimental}

2.1. Catalysts Preparation. In this study, a commonly used solvothermal method was employed to synthesize In and $\mathrm{P}-\mathrm{TiO}_{2}$ catalysts. The reagents used for the preparation of sol mixture were titanium tetraisopropoxide (99.95\%, Junsei Chemical, Japan), indium trichloride (98\%, Aldrich, USA) and phosphoric acid (Wako Pure Chem. Ltd., Japan) as Ti, In, and $\mathrm{P}$ precursors, respectively. The metal precursors were mixed with ethyl alcohol (99\%, Wako Pure Chem. Ltd., Japan) in an autoclave (model R-211, Reaction Engineering Inc., Korea) heated at $200^{\circ} \mathrm{C}$ for $10 \mathrm{~h}$ at a rate of $10^{\circ} \mathrm{C} \mathrm{min} \mathrm{m}^{-1}$. During the thermal treatment, Ti, In, and $\mathrm{P}$ were hydrolyzed by the hydroxyl group in solvent leading to the formation of nanosized In and $\mathrm{P}-\mathrm{TiO}_{2}$ crystals. The resulting powder was washed with distilled water until $\mathrm{pH}-7$ was reached and then dried. Finally, the samples were thermally treated at two different temperatures, 500 and $800^{\circ} \mathrm{C}$, for $3 \mathrm{~h}$ to remove impurities like the residual carbon or chloride ions on the powder surface and also to study the effect of calcination on the phase formation in the prepared catalysts.

2.2. Characterizations. The prepared catalysts were identified through powder X-ray diffraction analysis (XRD, model PW 1830, Philips, The Netherlands) with nickel-filtered $\mathrm{Cu} \mathrm{K} \alpha$ radiation $(40 \mathrm{kV}, 100 \mathrm{~mA})$ at $2 \theta$ angles of 5 to $90^{\circ}$. The scan speed was $10^{\circ} \mathrm{min}^{-1}$, and the time constants were $1 \mathrm{sec}$. The scanning electron microscopy (SEM) images were obtained using Leica 440, Beam source is tungsten filament, resolution is $4.5 \mathrm{~nm}$, and probe current was in between $1 \mathrm{pA}$ to $1 \mu \mathrm{A}$.

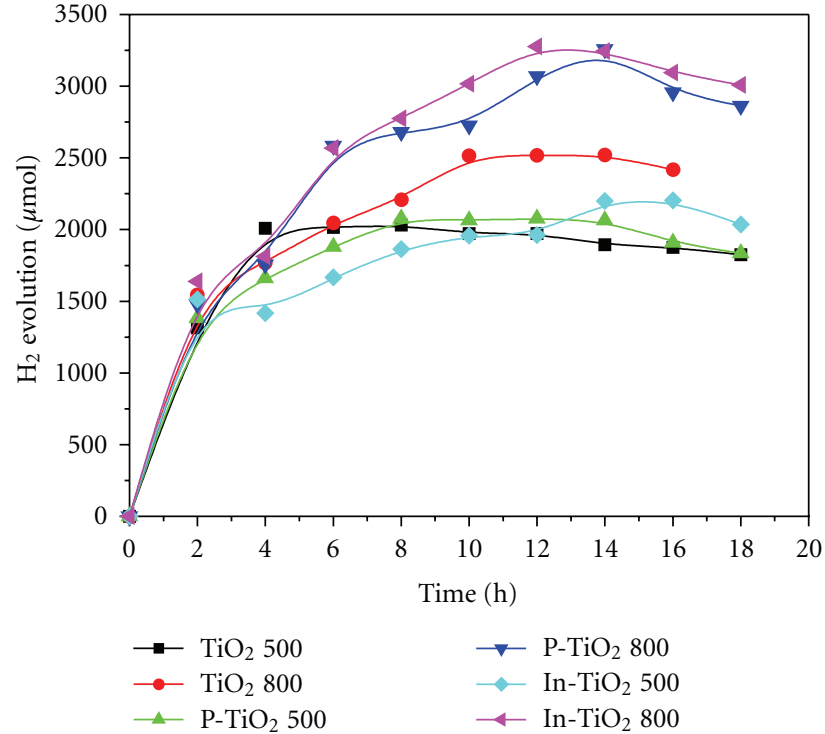

FIgure 1: Catalytic activity of $1 \mathrm{~mol} \% \mathrm{P}$, In- $-\mathrm{TiO}_{2}$, and $\mathrm{TiO}_{2}$ with rutile and anatase phases during the production of $\mathrm{H}_{2}$ from methanol/water photodecomposition.

For analysis of the binding energy among In3d, P2p, Ti2p, and $\mathrm{O} 1 \mathrm{~s}$, the X-ray photoelectron spectroscopy (XPS, PHI 5700, PHI com) was employed. The $1.0 \mathrm{~mol} \% \mathrm{In}$ and $\mathrm{P}$ incorporated $\mathrm{TiO}_{2}$ powder were pelletized at $2.0 \times 10^{4} \mathrm{kPa}$ for $10 \mathrm{~min}$; the $1.0 \mathrm{~mm}$ sized pellets were then maintained overnight in a vacuum oven $\left(1.0 \times 10^{-7} \mathrm{~Pa}\right)$ to remove the surface water molecules prior to measurement. The case pressure of the ESCA system was below $1 \times 10^{-9} \mathrm{~Pa}$. The experiments were recorded using a $200 \mathrm{~W}$ power source and angular acceptance of $\pm 5^{\circ}$, with the analyzer axis set at an angle of $90^{\circ}$ to the specimen surface. Wide scan spectra were measured over the binding energy range 0 to $1200 \mathrm{eV}$, with pass energy of $100.0 \mathrm{eV}$. The Ar+ bombardments of the $1.0 \mathrm{~mol} \% \mathrm{In}, \mathrm{P}$ incorporated $\mathrm{TiO}_{2} \mathrm{~s}$ were performed with ion currents between 70 and $100 \mathrm{nA}$, over a $10.0 \times 10.0 \mathrm{~mm}$ area, with a total sputtering time of $2400 \mathrm{~s}$, divided into $60 \mathrm{~s}$ intervals. The UV-visible spectrum was obtained using a JASCO V-570 spectrometer equipped with a reflectance sphere. The spectral range varied from 200 to $800 \mathrm{~nm}$. Photoluminescence spectroscopy was measured at room temperature using a Phillips $\mathrm{H}-9000$ using $\mathrm{HeCd}$ as the beam source at $325 \mathrm{~nm}$.

\section{3. $\mathrm{H}_{2}$ Production from Methanol/Water Decomposition over} In, $\mathrm{P}-\mathrm{TiO}_{2}$. In general, water decomposition systems are based on the evaluation of accumulated $\mathrm{H}_{2}$ from water, and most of the systems employ semi-batch type reactors like plug flow reactor. In our study, we used a custommade liquid photoreactor setup for the photodecomposition of methanol/water. For hydrogen generation, $1.0 \mathrm{~g}$ of the powdered catalysts was added to $500 \mathrm{ml}$ each of distilled water and methanol in a $1300 \mathrm{~mL}$ Pyrex reactor. UV-lamps $\left(3 \times 6 \mathrm{Wcm}^{-2}, 15 \mathrm{~cm}\right.$ length $\times 2.0 \mathrm{~cm}$ diameter $)$ emitting radiation at $365 \mathrm{~nm}$ were used. A flask for hydrogen storage 


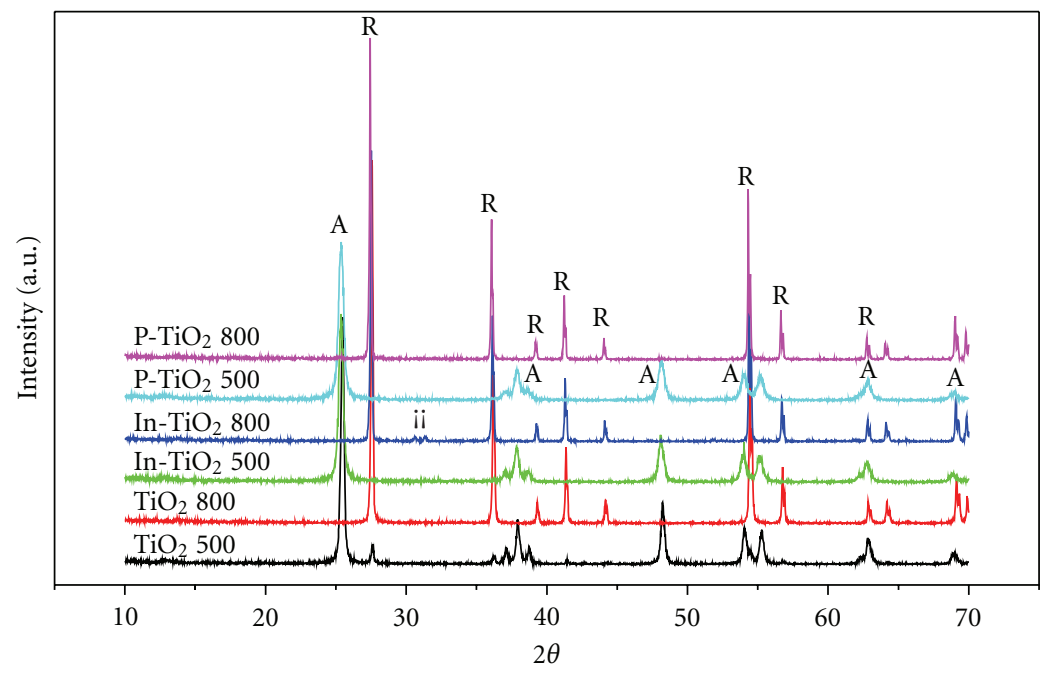

A-Anatase

R-Rutile

i- $-\mathrm{In}_{2} \mathrm{O}_{3}$

FIgURE 2: XRD patterns of $1.0 \mathrm{~mol} \% \mathrm{P}, \mathrm{In}-\mathrm{TiO}_{2}$, and $\mathrm{TiO}_{2}$ photocatalysts treated at $500^{\circ} \mathrm{C}$ (anatase phase) and $800^{\circ} \mathrm{C}$ (rutile phase).

collects the product from reactor using a vacuum pump. The produced hydrogen was analyzed by GC/TCD (Shimadzu 17A, Japan) using molecular seive-5A column.

\section{Results and Discussion}

3.1. $\mathrm{H}_{2}$ Production from Hydrolysis of Water with Methanol on In, $\mathrm{P} \mathrm{TiO}_{2}$ s Photocatalysts. Figure 1 shows the catalytic activity of In and $\mathrm{P}-\mathrm{TiO}_{2}$ with anatase and rutile phase for the production of $\mathrm{H}_{2}$ from methanol/water photodecomposition. Unfortunately, the GC detector could not sense the $\mathrm{H}_{2}$ production until $2 \mathrm{~h}$ had elapsed because too little product had decomposed. Then rate of $\mathrm{H}_{2}$ evolution becomes very stable after $2 \mathrm{~h}$, and activities reach to steadystate at $8 \mathrm{~h}$. However In, $\mathrm{P}$ incorporated $\mathrm{TiO}_{2}$ increase rate of $\mathrm{H}_{2}$ evolution until $12 \mathrm{~h}$. In general, previous researchers plotted continuously increasing graph because $\mathrm{H}_{2}$ production accumulated by using batch system [4-13]. While, in this study, used system for $\mathrm{H}_{2}$ evolution is semi-batch system, it can be calculated $\mathrm{H}_{2}$ production per hour. So, the time to reach steady state can be obtained, and the graph could not increase continuously. The catalysts with rutile phase exhibit relatively higher activity than those with anatase phase in a semi-batch type liquid photosystem. The maximum $\mathrm{H}_{2}$ production of $3,300 \mu \mathrm{mol}$ at about $12 \mathrm{~h}$ was achieved for In- $\mathrm{TiO}_{2}$ calcined at $800^{\circ} \mathrm{C}$ (rutile structure), and with further increase in time, a small decrease in its activity was observed. The increasing activity of the added In and P catalysts may be caused by increased reduction activity, substantial increase in the rate of photo absorption, and change of atomic bonding and composition of catalyst surface.

3.2. Characterization of $\mathrm{In}, \mathrm{P}-\mathrm{TiO}_{2}$ Catalysts. Figure 2 shows the XRD patterns of $\mathrm{P}-\mathrm{TiO}_{2}, \mathrm{In}-\mathrm{TiO}_{2}$, and $\mathrm{TiO}_{2}$ powders treated at 500 and $800^{\circ} \mathrm{C}$. Depending on the calcination treatment temperature, well-developed anatase $\left(500^{\circ} \mathrm{C}\right)$ and rutile $\left(800^{\circ} \mathrm{C}\right)$ phases were formed, and their diffraction pattern are labeled as " $\mathrm{A}$ " and " $\mathrm{R}$ ", respectively. The peaks of the In, $\mathrm{P}$ are very well inserted into the $\mathrm{TiO}_{2}$ structure and that explains the absence of their peaks in Figure 2. The peaks corresponding to anatase were assigned as $2 \theta=$ $25.2^{\circ}(101), 37.5^{\circ}(004), 47.5^{\circ}(220), 53.8^{\circ}(105), 54.9^{\circ}$ (211), $63.0^{\circ}$ (204); for rutile as $2 \theta=27.5^{\circ}(110), 36.1^{\circ}(101), 41.3^{\circ}$ (111), $54.4^{\circ}(211), 56.7^{\circ}(220)$. Especially, rutile phase of In incorporated $\mathrm{TiO}_{2}$ appears peak of $\mathrm{In}_{2} \mathrm{O}_{3}$ at $2 \theta=30.6^{\circ}, 31.4^{\circ}$. It is considered that indium is formed crystalline easily than phosphorus by effect of sintering [14].

Figure 3 shows SEM micrographs of $\mathrm{TiO}_{2}, \mathrm{In}-\mathrm{TiO}_{2}$, and $\mathrm{P}-\mathrm{TiO}_{2}$ particles. The photocatalysts consisted of relatively irregular and spherical particles of varied size between 50 to $500 \mathrm{~nm}$. Among them, the particles with anatase structure prepared at $500^{\circ} \mathrm{C}$ were smaller than those with the rutile structure prepared at $800^{\circ} \mathrm{C}$. This result is related to a sintering effect in which the particle size increases with the calcination temperature due to the increased agglomeration of the particles. Also, $\mathrm{TiO}_{2}$ without additive material is composed of granules with a smooth surface. However, after incorporating In and $\mathrm{P}$ on $\mathrm{TiO}_{2}$, the granules became irregular and angular with the grain size of about $0.3-50 \mu \mathrm{m}$.

XPS analysis of $\mathrm{O} 1 \mathrm{~s}$ and $\mathrm{Ti} 2 \mathrm{p}$ orbital of $\mathrm{TiO}_{2}$, In$\mathrm{TiO}_{2}$, and $\mathrm{P}-\mathrm{TiO}_{2}$ are shown in Figure 4 . The Ti $2 \mathrm{p}_{1 / 2}$ and $\mathrm{Ti}$ $2 \mathrm{p}_{3 / 2}$ spin-orbital splitting photoelectrons for anatase $\mathrm{TiO}_{2}$ were located at biding energies of 464.34 and $458.57 \mathrm{eV}$, which were assigned to the presence of general $\operatorname{Ti}^{4+}[15$, 16] as shown in Figure 4(a). From Figure 4(b), the binding energy of Ti $2 p$ orbital was observed to decrease due to the added In and P which infers the transformation from higher 

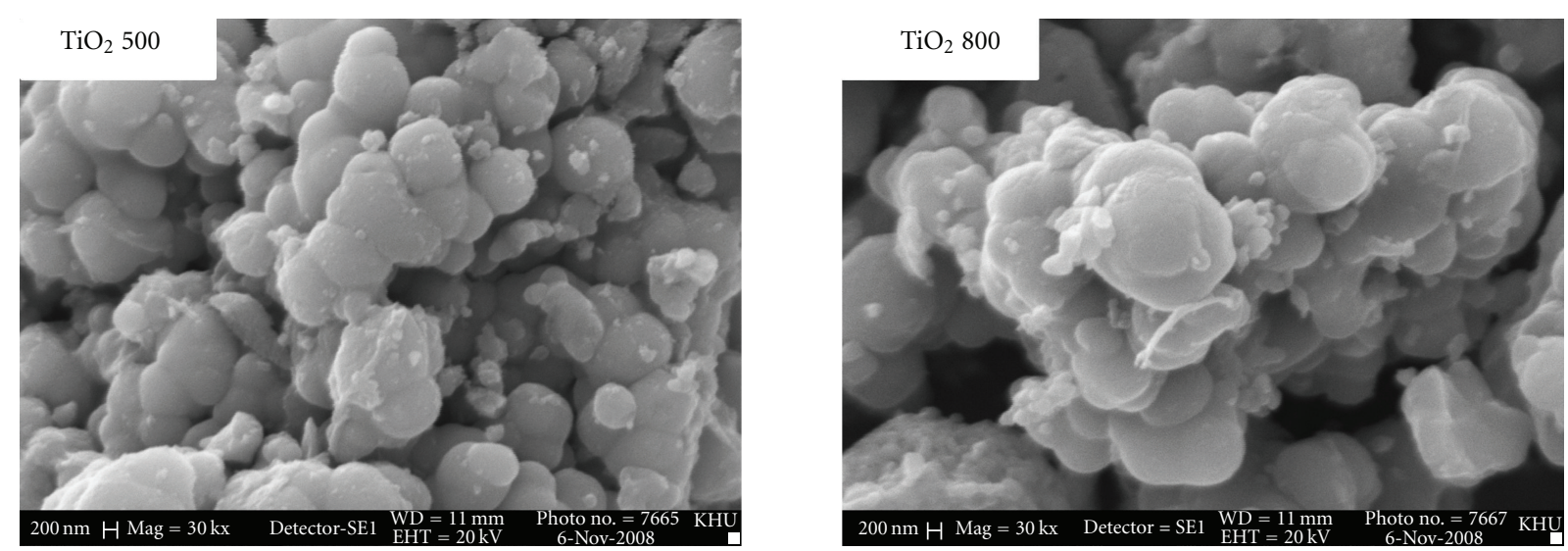

(a) $\mathrm{TiO}_{2}$
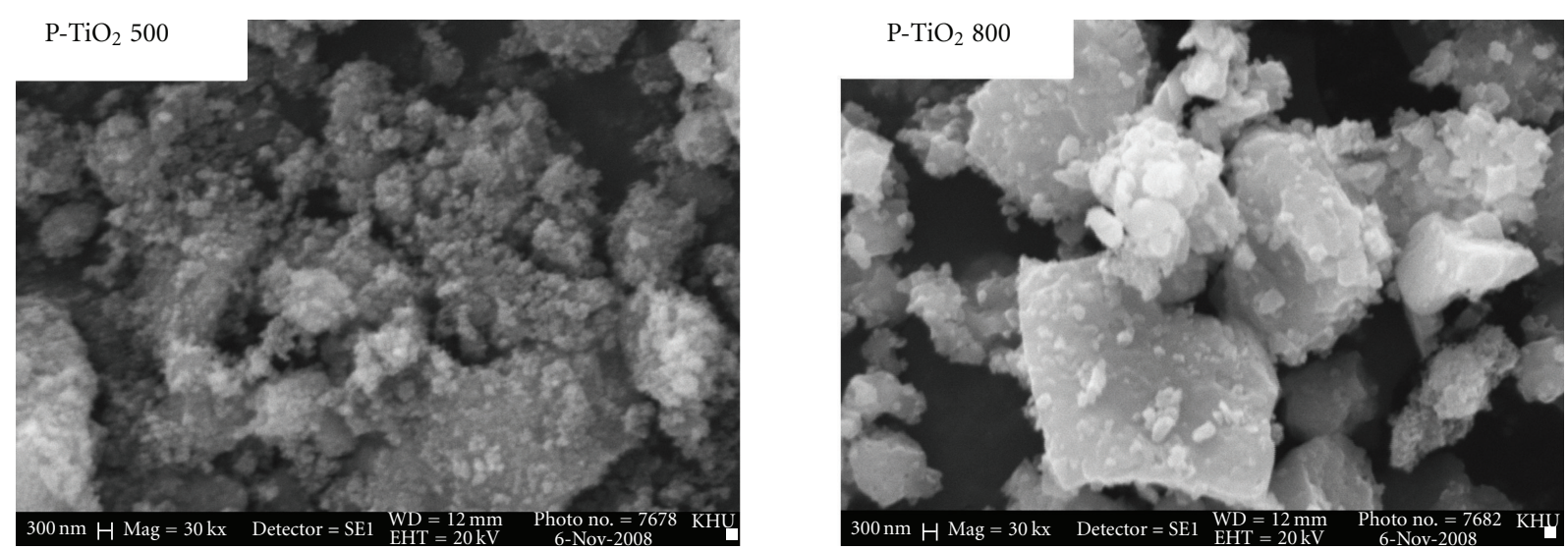

(b) $\mathrm{P}_{-} \mathrm{TiO}_{2}$
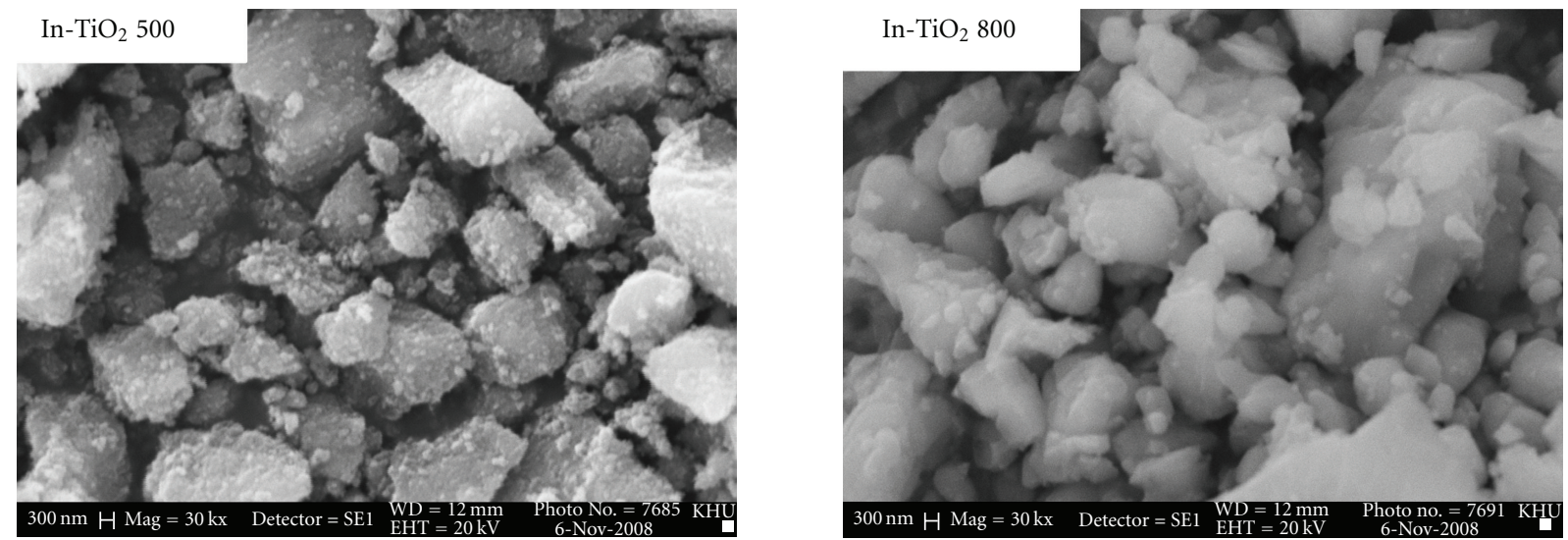

(c) $\mathrm{In}-\mathrm{TiO}_{2}$

Figure 3: SEM micrographs of (a) $\mathrm{TiO}_{2}$ (b) $\mathrm{P}-\mathrm{TiO}_{2}$, and (c) $\mathrm{In}-\mathrm{TiO}_{2}$ photocatalysts treated at $500^{\circ} \mathrm{C}$ (anatase phase) and $800^{\circ} \mathrm{C}$ (rutile phase).

$\mathrm{Ti}^{4+}$ to lower $\mathrm{Ti}^{3+}$ valence state. Generally, a high binding energy means that the metal has a high valence [17]. At this situation, an increase in catalytic activity is expected to change valence as $\mathrm{Ti}^{3+}$. In the case of $\mathrm{O} 1$ s (Figure 4(c)), the two overlapping peaks were isolated using the Gaussian method. The $\mathrm{O} 1 \mathrm{~s}$ peaks at 529.8 and $531.20 \mathrm{eV}$ were assigned to metal oxidation and metal hydroxyl group, respectively.
With increasing area of the hydroxyl group, the hydrophilic and catalytic activities are expected to increase.

From Figure 5, the In $3 \mathrm{~d}_{5 / 2}$ and $\mathrm{P} 2 \mathrm{p}_{3 / 2}$ spin-orbital splitting photoelectrons were located at the biding energies of $444.03 \mathrm{eV}$ and $133.02 \mathrm{eV}$ which is identified with the oxidation state of $\mathrm{In}^{3+}$ and $\mathrm{P}^{5+}$, respectively in $\mathrm{TiO}_{2}$. Especially, the existence of phosphorous in the pentavalent oxidation 


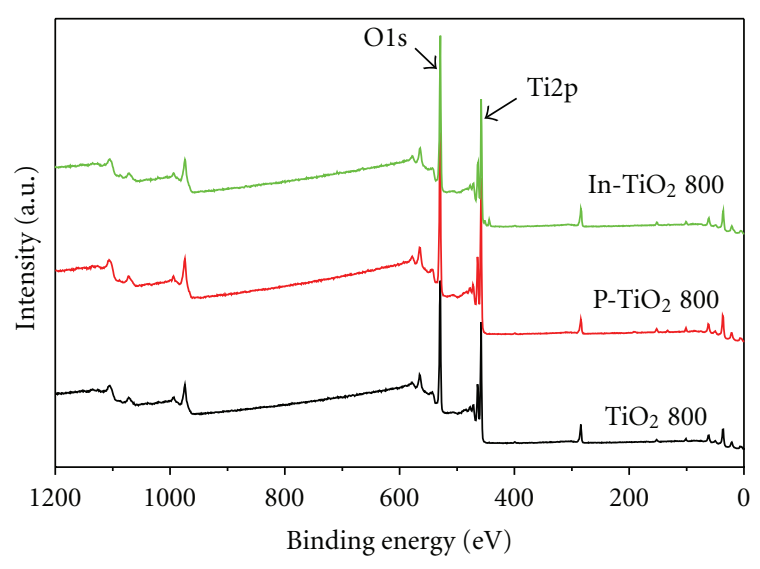

(a)

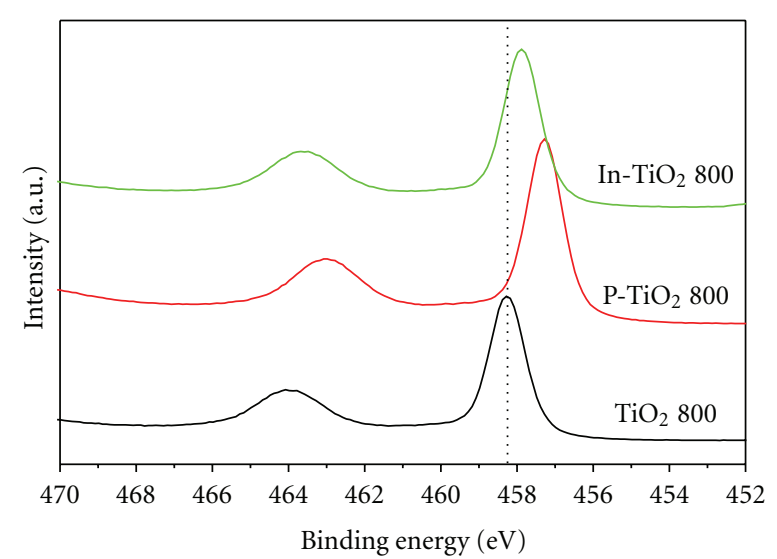

(b) $\operatorname{Ti} 2 \mathrm{p}_{3 / 2}$

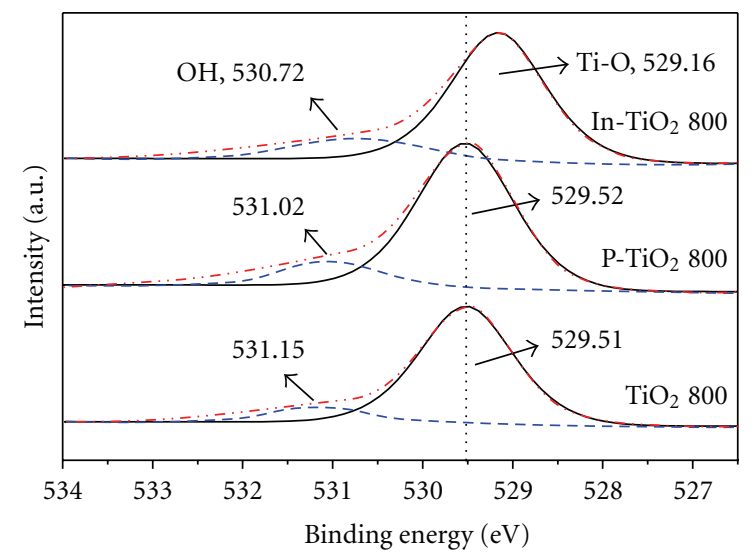

(c) $\mathrm{O} 1 \mathrm{~s}$

Figure 4: XPS analysis of (a) $1.0 \mathrm{~mol} \% \mathrm{In}, \mathrm{P}$ incorporated $\mathrm{TiO}_{2}$ photocatalysts; (b) $\mathrm{Ti} 2 \mathrm{p}$ and (c) $\mathrm{O}$ 1s spin orbital.

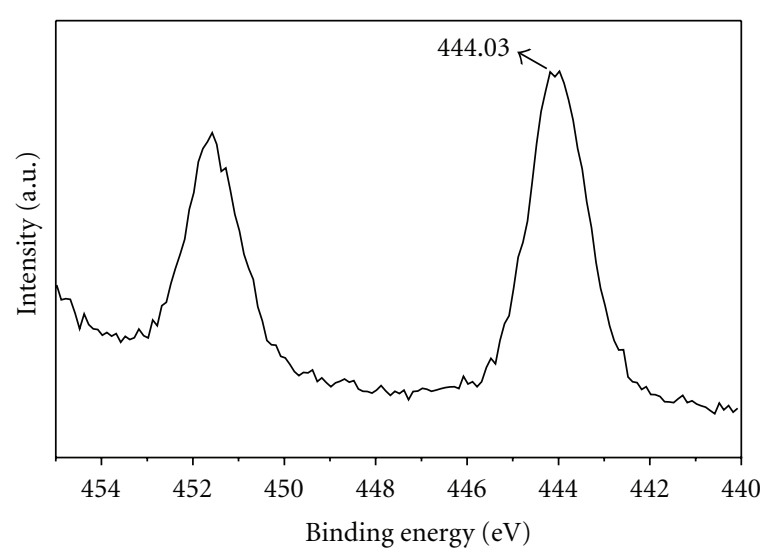

(a) In $3 d_{5 / 2}$

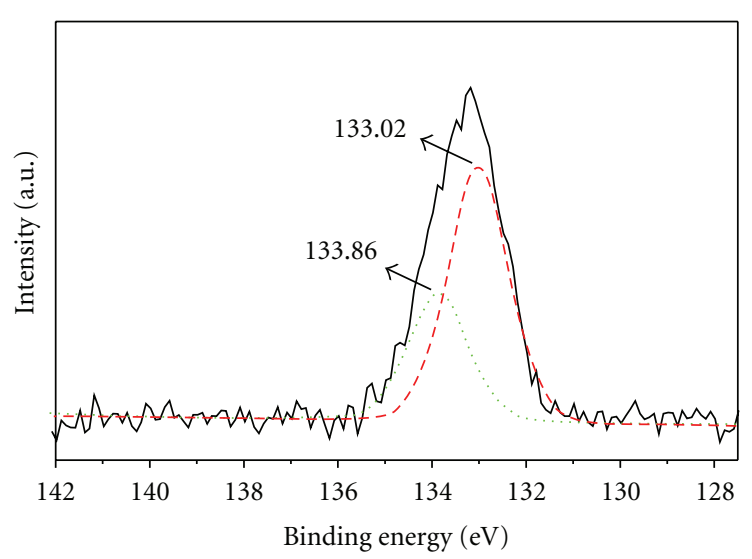

(b) $\mathrm{P} 2 \mathrm{p}_{3 / 2}$

FIGURE 5: XPS analysis of $1.0 \mathrm{~mol} \% \mathrm{In}, \mathrm{P}$ incorporated $\mathrm{TiO}_{2}$ photocatalysts treated at $800^{\circ} \mathrm{C}$; (a) In $3 \mathrm{~d}$ and (b) P $2 \mathrm{p}$ spin orbital.

state has a decreasing effect on valence-hole recombination because of the unbalanced electrical charge [18].

UV-Vis spectroscopy was used to examine the light absorption ability of the investigated photocatalysts as shown in Figure 6. The onset absorption wavelength and corresponding band gap energy of the photocatalysts used in this study as obtained from the UV-Vis spectra are summarized in Table 1. It is clearly seen that the absorption band of the synthesized In and $\mathrm{P}-\mathrm{TiO}_{2}$ is in the UV light range of 200 to $400 \mathrm{~nm}$, and the shift of the onset absorption edges toward longer wavelength with rutile and anatase form [19]. 
TABLE 1: Summary of the onset absorption wavelengths, band gap energies, and chemical composition of $1.0 \mathrm{~mol} \% \mathrm{In}, \mathrm{P}$ incorporated TiO 2 photocatalysts.

\begin{tabular}{|c|c|c|c|c|c|c|c|c|}
\hline \multirow{2}{*}{ Photocatalyst } & \multirow{2}{*}{$\begin{array}{l}\text { Calcination } \\
\text { temperature }\left({ }^{\circ} \mathrm{C}\right)\end{array}$} & \multirow{2}{*}{$\begin{array}{l}\text { Onset absorption } \\
\text { wavelength, } \lambda \mathrm{g}(\mathrm{nm})\end{array}$} & \multirow{2}{*}{ Band gap energy $(\mathrm{eV})$} & \multicolumn{5}{|c|}{ Element (wt.\%) } \\
\hline & & & & $\mathrm{OK}$ & $\mathrm{Ti} \mathrm{K}$ & P K & In $\mathrm{L}$ & Totals \\
\hline $\mathrm{TiO}_{2}-\mathrm{A}$ & 500 & 418 & 2.97 & & & & & \\
\hline $\mathrm{TiO}_{2}-\mathrm{R}$ & 800 & 430 & 2.88 & 39.88 & 60.12 & & & 100.0 \\
\hline In $-\mathrm{TiO}_{2}-\mathrm{A}$ & 500 & 407 & 3.05 & & & & & \\
\hline In $-\mathrm{TiO}_{2}-\mathrm{R}$ & 800 & 439 & 2.82 & 44.23 & 55.26 & & 0.51 & 100.0 \\
\hline $\mathrm{P}-\mathrm{TiO}_{2}-\mathrm{A}$ & 500 & 402 & 3.08 & & & & & \\
\hline $\mathrm{P}-\mathrm{TiO}_{2}-\mathrm{R}$ & 800 & 425 & 2.92 & 43.01 & 56.47 & 0.52 & & 100.0 \\
\hline
\end{tabular}

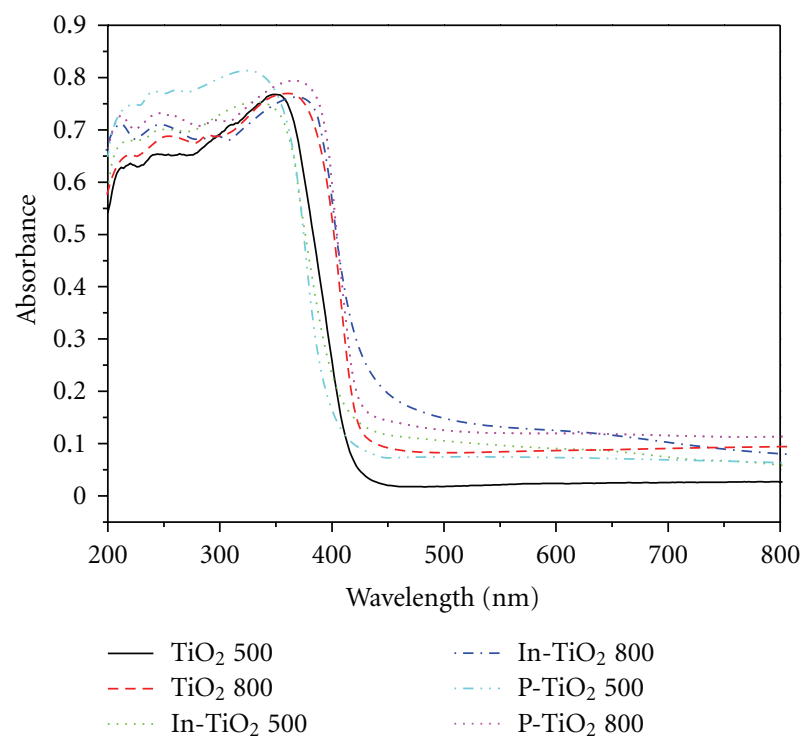

Figure 6: UV-Visible spectroscopy of $1.0 \mathrm{~mol} \% \mathrm{In}, \mathrm{P}$ incorporated $\mathrm{TiO}_{2}$ photocatalysts.

Figure 7 shows photoluminescence emission on $\mathrm{In}-\mathrm{TiO}_{2}$, $\mathrm{P}-\mathrm{TiO}_{2}$, and pure $\mathrm{TiO}_{2}$. The objective of this experiment is to study the addition of In and P on the electrohole recombination rate. According to the test results, the shape of the peak discloses no change in the spectrum of the used catalysts. However, the peak intensity decreases depending on the doping level of In and $\mathrm{P}$ in $\mathrm{TiO}_{2}$. Generally, when photoluminescence emission value is large, the numbe of recombination electrons should also large number of electrons are photoexcited. Therefore, the larger the emission value is, the photocatalytic reaction might be. However, in this study the higher the photoluminescence emission values were, the lower the photocatalytic activities that could be indicated. The result could be thought that the metal incorporated $\mathrm{TiO}_{2}$, the amount of recombination of electron-hole pairs is decreased, which could be due to photoexcited electrons joining in photocatalytic reaction rather than recombining with holes emitting the absorbed energy [20-23].

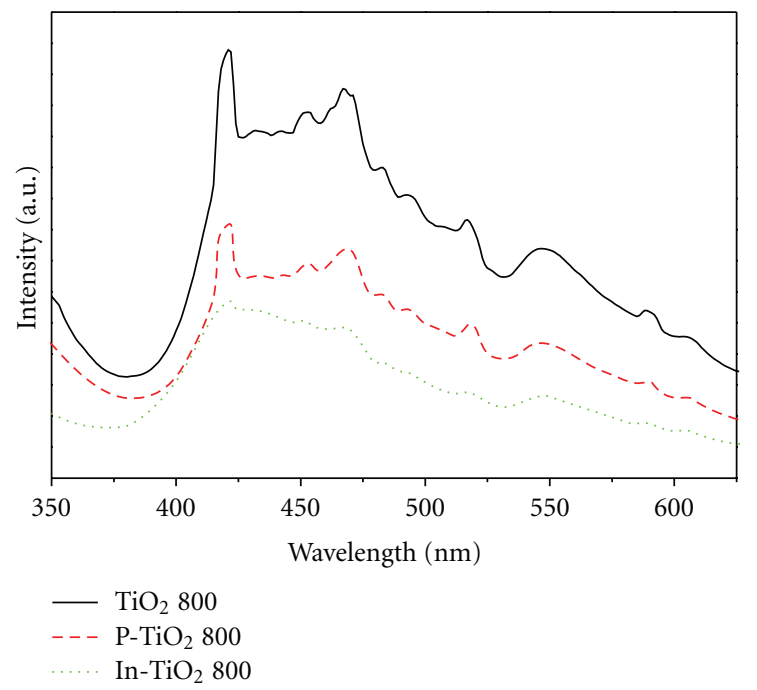

FIgure 7: Photoluminescence spectra of $1.0 \mathrm{~mol} \% \mathrm{In}, \mathrm{P}$ incorporated $\mathrm{TiO}_{2}$ photocatalysts.

\section{Conclusions}

This study focused on using In, $\mathrm{P}$ incorporated $\mathrm{TiO}_{2}$ catalysts synthesized by solvothermal method and used for the production of $\mathrm{H}_{2}$ from methanol/water photodecomposition. Compared to anatase structure, the rutile form exhibited better $\mathrm{H}_{2}$ production from methanol/water photodecomposition. Compared to $\mathrm{P}-\mathrm{TiO}_{2}$, the production of $\mathrm{H}_{2}$ was a little better in the case of $\mathrm{In}-\mathrm{TiO}_{2}$ and also showed a $30 \%$ increase in the activity than pure $\mathrm{TiO}_{2}$. The well-defined dispersion of the metal in the $\mathrm{TiO}_{2}$ was confirmed from XRD result. Increase of the $\mathrm{OH}$ group on the catalytic surface, change of Ti structure, increase in the absorption of visible light, and decrease of valence-hole recombination were confirmed using XPS, UV-Vis, and PL data. The prepared catalysts were found to exhibit good activity than pure $\mathrm{TiO}_{2}$, and our future studies will focus on further improving the catalytic activity.

\section{Acknowledgment}

The authors are grateful to the Financial Grant (KRF20090088941) provided by the Korea Research Foundation. 


\section{References}

[1] A. Fujishima and K. Honda, "Electrochemical photolysis of water at a semiconductor electrode," Nature, vol. 238, no. 5358, pp. 37-38, 1972.

[2] T. Kawai and T. Sakata, "Photocatalytic hydrogen production from liquid methanol and water," Journal of the Chemical Society, Chemical Communications, no. 15, pp. 694-695, 1980.

[3] J. Chen, D. F. Ollis, W. H. Rulkens, and H. Bruning, "Photocatalyzed oxidation of alcohols and organochlorides in the presence of native $\mathrm{TiO}_{2}$ and metallized $\mathrm{TiO}_{2}$ suspensions. Part (II): photocatalytic mechanisms," Water Research, vol. 33, no. 3, pp. 669-676, 1999.

[4] M. Anpo and M. Takeuchi, "The design and development of highly reactive titanium oxide photocatalysts operating under visible light irradiation," Journal of Catalysis, vol. 216, no. 1-2, pp. 505-516, 2003.

[5] G. R. Bamwenda, S. Tsubota, T. Nakamura, and M. Haruta, "The influence of the preparation methods on the catalytic activity of platinum and gold supported on $\mathrm{TiO}_{2}$ for $\mathrm{CO}$ oxidation," Catalysis Letters, vol. 44, no. 1-2, pp. 83-87, 1997.

[6] S. Sakthivel, M. V. Shankar, M. Palanichamy, B. Arabindoo, D. W. Bahnemann, and V. Murugesan, "Enhancement of photocatalytic activity by metal deposition: characterisation and photonic efficiency of $\mathrm{Pt}, \mathrm{Au}$ and $\mathrm{Pd}$ deposited on $\mathrm{TiO}_{2}$ catalyst," Water Research, vol. 38, no. 13, pp. 3001-3008, 2004.

[7] Y. Wu, G. Lu, and S. Li, "The role of $\mathrm{Cu}(\mathrm{I})$ species for photocatalytic hydrogen generation over $\mathrm{CuO}_{\mathrm{x}} / \mathrm{TiO}_{2}$," Catalysis Letters, vol. 133, no. 1-2, pp. 97-105, 2009.

[8] J. W. Park and M. Kang, "Synthesis and characterization of $\operatorname{Ag}_{\mathrm{x}} \mathrm{O}$, and hydrogen production from methanol photodecomposition over the mixture of $\mathrm{Ag}_{\mathrm{x}} \mathrm{O}$ and $\mathrm{TiO}_{2}$," International Journal of Hydrogen Energy, vol. 32, no. 18, pp. 4840-4846, 2007.

[9] W. Choi, A. Termin, and M. R. Hoffmann, "The role of metal ion dopants in quantum-sized $\mathrm{TiO}_{2}$ : correlation between photoreactivity and charge carrier recombination dynamics," Journal of Physical Chemistry, vol. 98, no. 51, pp. 13669-13679, 1994.

[10] K. R. Reyes-Gil, E. A. Reyes-García, and D. Raftery, "Photoelectrochemical analysis of anion-doped $\mathrm{TiO}_{2}$ colloidal and powder thin-film electrodes," Journal of the Electrochemical Society, vol. 153, no. 7, pp. A1296-A1301, 2006.

[11] S. Klosek and D. Raftery, "Visible light driven V-doped $\mathrm{TiO}_{2}$ photocatalyst and its photooxidation of ethanol," Journal of Physical Chemistry B, vol. 105, no. 14, pp. 2815-2819, 2002.

[12] A. Di Paola, G. Marcì, L. Palmisano et al., "Preparation of polycrystalline $\mathrm{TiO}_{2}$ photocatalysts impregnated with various transition metal ions: characterization and photocatalytic activity for the degradation of 4-nitrophenol," Journal of Physical Chemistry B, vol. 106, no. 3, pp. 637-645, 2002.

[13] E. P. Reddy, BO. Sun, and P. G. Smirniotis, “Transition metal modified $\mathrm{TiO}_{2}$-loaded MCM-41 catalysts for visible- and UVlight driven photodegradation of aqueous organic pollutants," Journal of Physical Chemistry B, vol. 108, no. 44, pp. 1719817205, 2004.

[14] Y. Chen, X. Zhou, X. Zhao, X. He, and X. Gu, "Crystallite structure, surface morphology and optical properties of $\mathrm{In}_{2} \mathrm{O}_{3}-\mathrm{TiO}_{2}$ composite thin films by sol-gel method," Materials Science and Engineering B, vol. 151, no. 2, pp. 179186, 2008.

[15] J. Yu, X. Zhao, Q. Zhao, and G. Wang, "Preparation and characterization of super-hydrophilic porous $\mathrm{TiO}_{2}$ coating films," Materials Chemistry and Physics, vol. 68, no. 1-3, pp. 253-259, 2001.

[16] Q. Liu, X. Wu, B. Wang, and Q. Liu, "Preparation and superhydrophilic properties of $\mathrm{TiO}_{2} / \mathrm{SnO}_{2}$ composite thin films," Materials Research Bulletin, vol. 37, no. 14, pp. 2255-2262, 2002.

[17] S. B. Kim, J. Y. Lee, H. T. Jang, W. S. Cha, and S. C. Hong, "Enhanced photocatalytic activity of $\mathrm{TiO}_{2}$ by metal doping for degradation of VOCs in air," Journal of Industrial and Engineering Chemistry, vol. 9, no. 4, pp. 440-446, 2003.

[18] X. Chen, X. Zhang, Y. Su, and L. Lei, "Preparation of visiblelight responsive $\mathrm{P}-\mathrm{F}$-codoped $\mathrm{TiO}_{2}$ nanotubes," Applied Surface Science, vol. 254, no. 20, pp. 6693-6696, 2008.

[19] T. Sreethawong, Y. Suzuki, and S. Yoshikawa, "Synthesis, characterization, and photocatalytic activity for hydrogen evolution of nanocrystalline mesoporous titania prepared by surfactant-assisted templating sol-gel process," Journal of Solid State Chemistry, vol. 178, no. 1, pp. 329-338, 2005.

[20] M. Anpo and M. Che, "Applications of photoluminescence techniques to the characterization of solid surfaces in relation to adsorption, catalysis, and photocatalysis," Advances in Catalysis, vol. 44, pp. 119-257, 1999.

[21] B. Y. Lee, S. H. Park, S. C. Lee, M. Kang, C. H. Park, and S. J. Choung, "Optical properties of $\mathrm{Pt}-\mathrm{TiO}_{2}$ catalyst and photocatalytic activities for benzene decomposition," Korean Journal of Chemical Engineering, vol. 20, no. 5, pp. 812-818, 2003.

[22] D. Dvoranová, V. Brezová, M. Mazúr, and M. A. Malati, "Investigations of metal-doped titanium dioxide photocatalysts," Applied Catalysis B, vol. 37, no. 2, pp. 91-105, 2002.

[23] X. Z. Li, F. B. Li, C. L. Yang, and W. K. Ge, "Photocatalytic activity of $\mathrm{WO}^{-\mathrm{TiO}_{2}}$ under visible light irradiation," Journal of Photochemistry and Photobiology A, vol. 141, no. 2-3, pp. 209217, 2001. 


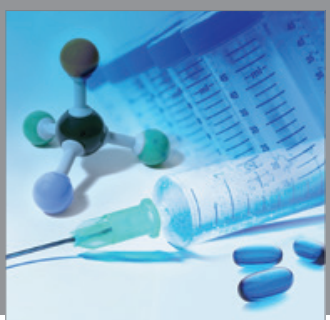

International Journal of

Medicinal Chemistry

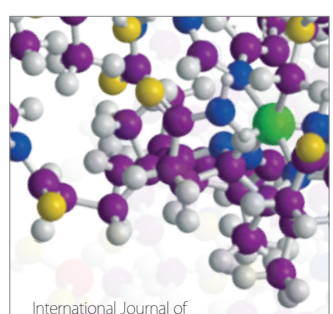

Carbohydrate Chemistry

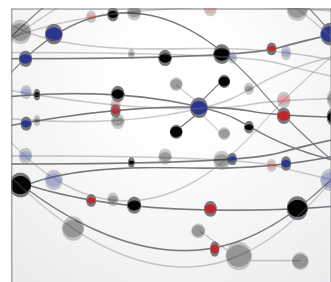

The Scientific World Journal
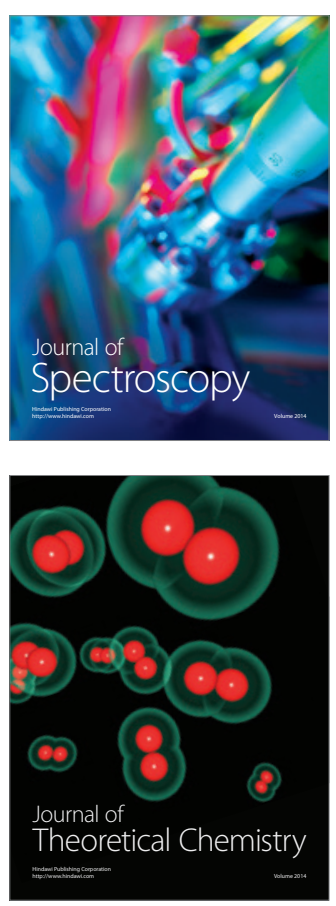
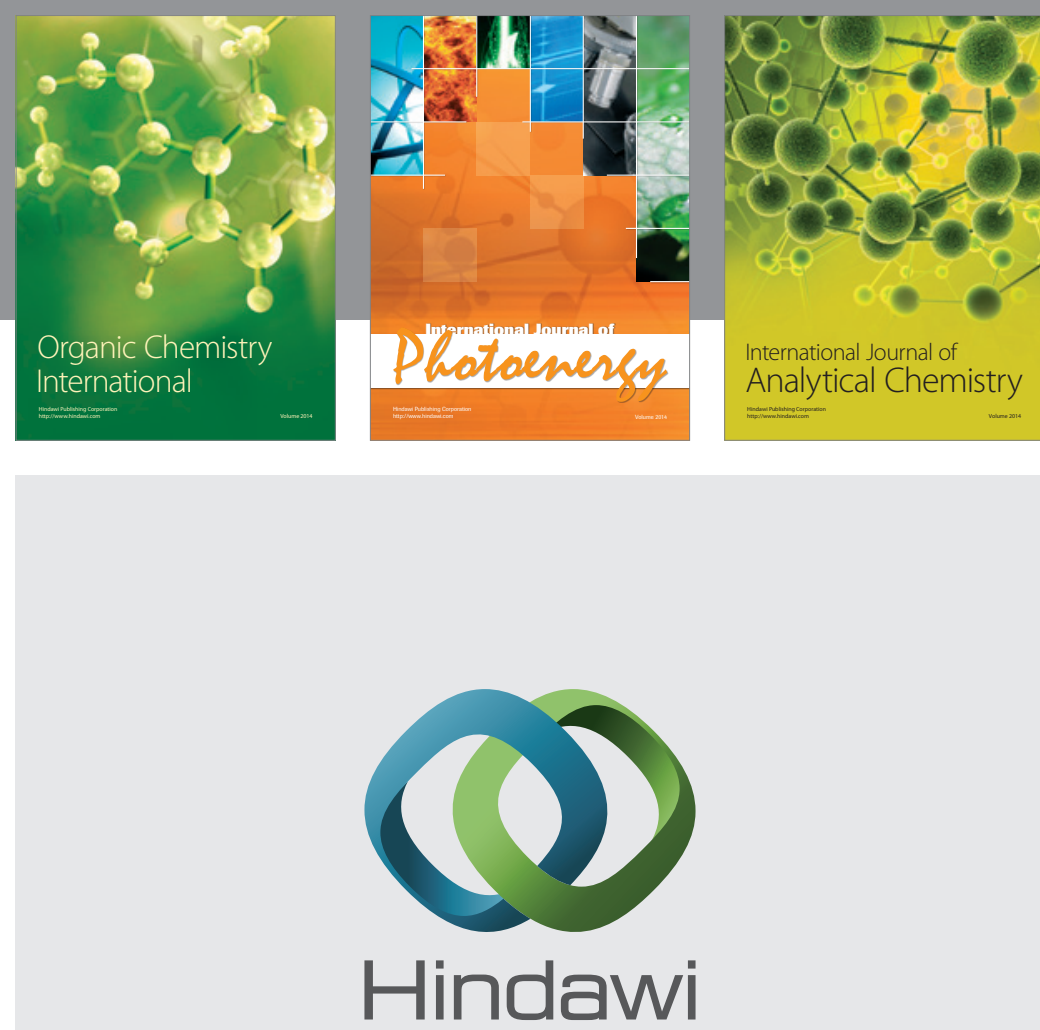

Submit your manuscripts at

http://www.hindawi.com
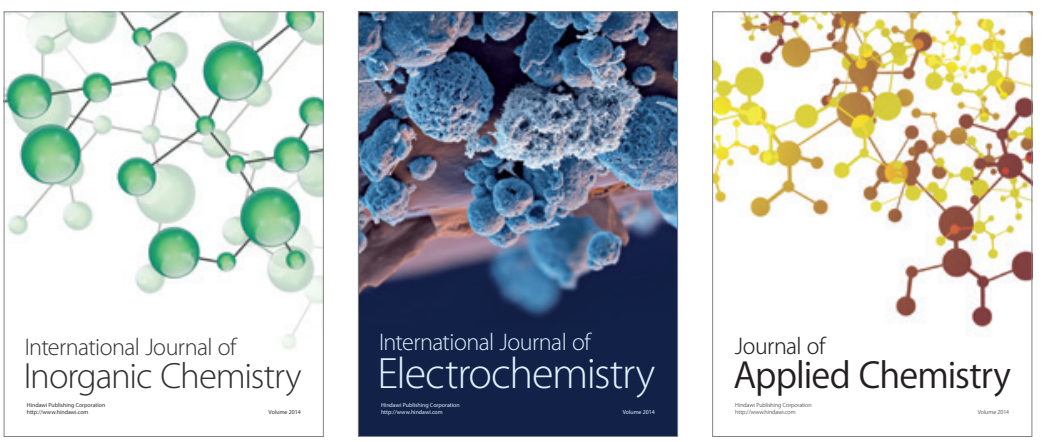

Journal of

Applied Chemistry
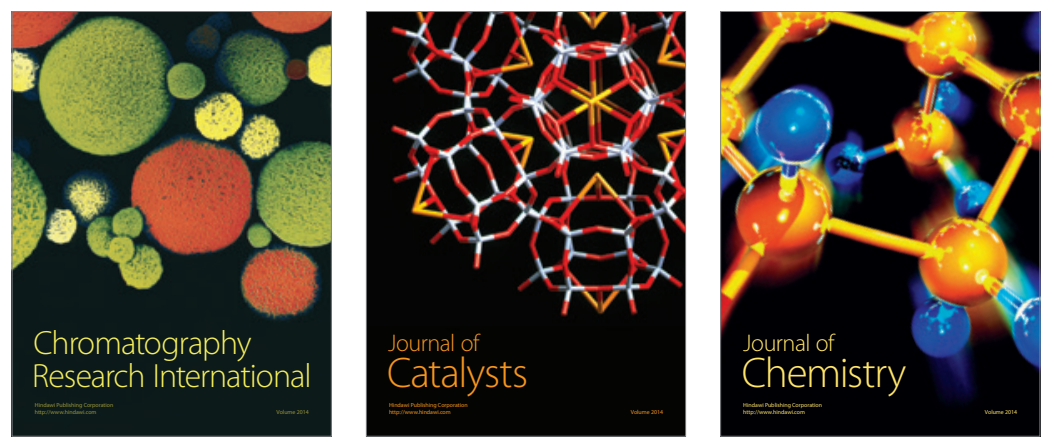
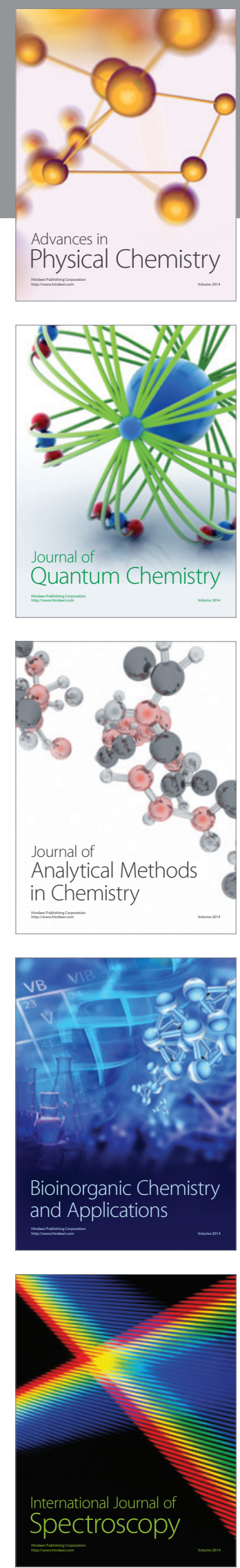